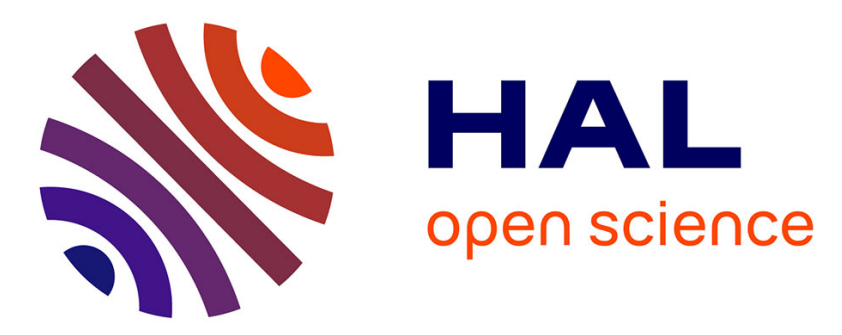

\title{
The Paths Between Gender, Barriers, Social Support, Coping Efficacy, and Educational Goals
}

\author{
Isabelle Fort, Anca Murariu
}

\section{To cite this version:}

Isabelle Fort, Anca Murariu. The Paths Between Gender, Barriers, Social Support, Coping Efficacy, and Educational Goals. Journal of Career Assessment, 2016, 26 (1), pp.68 - 76. $10.1177 / 1069072716679924$. hal-01791022

\section{HAL Id: hal-01791022 \\ https://hal-amu.archives-ouvertes.fr/hal-01791022}

Submitted on 15 May 2018

HAL is a multi-disciplinary open access archive for the deposit and dissemination of scientific research documents, whether they are published or not. The documents may come from teaching and research institutions in France or abroad, or from public or private research centers.
L'archive ouverte pluridisciplinaire HAL, est destinée au dépôt et à la diffusion de documents scientifiques de niveau recherche, publiés ou non, émanant des établissements d'enseignement et de recherche français ou étrangers, des laboratoires publics ou privés. 
Gender, Barriers, Support, Self-Efficacy and Goals

The Paths Between Gender, Barriers, Social Support, Coping Efficacy and Educational Goals

Isabelle Fort, Anca Murariu 


\title{
Gender, Barriers, Support, Self-Efficacy and Goals
}

\begin{abstract}
The twofold aim of this study was first to extend results on the career choice model previously obtained with students in science, technology, engineering and mathematics, and to gauge the relevance of including self-efficacy for coping with barriers in this model. The second aim was to examine whether examined paths varied according to gender. We investigated the paths between social support, barriers, barrier coping efficacy, and goals in a sample of 215 students drawn from disciplines where men are underrepresented. In line with the hypothetical model, results revealed significant paths between social support, barriers, barrier coping efficacy and goals. Moreover, these paths did not vary according to gender. Results are discussed with reference to the literature and in terms of their practical implications.
\end{abstract}

Keywords: social support, barriers, barrier coping efficacy, gender, goals 


\section{Gender, Barriers, Support, Self-Efficacy and Goals}

\section{Gender, Barriers, Support, Coping Efficacy and Educational Goals}

Social cognitive career theory (SCCT) is well rooted in vocational psychology. This theory essentially postulates that career interests, goals and actions are determined by both individual and contextual factors. Several models have been constructed on the basis of this theory, including the interest development, choice behaviour, and performance models (Lent, 2008). These have all been extensively investigated. In studies validating the career choice model, for instance, authors have investigated the relationships between self-efficacy, outcome expectations, contextual variables (perceived barriers and social support), interests, and goals (Inda, Rodríguez, \& Peña, 2013; Jiang \& Zhang, 2012; Lent et al., 2005; Lent, Lopez, Lopez, \& Sheu, 2008). These studies showed that perceived barriers and social support are related to goals both directly and indirectly, through self-efficacy, outcome expectations and interests (Garriott, Flores, \& Martens, 2013; Inda et al., 2013; Lent et al., 2008; Lent, Lopez, Sheu, \& Lopez, 2011).

The measures of self-efficacy used in these studies included items relating either to both self-efficacy for coping with barriers (coping efficacy) and academic self-efficacy, or to academic self-efficacy only (Garriott et al., 2013; Navarro, Flores, \& Worthington, 2007). The latter's specific role in the career choice model has therefore already been investigated (Blanco, 2011; Garriott et al., 2013; Navarro et al., 2007). By contrast, the specific role of coping efficacy could not be examined in these studies, because the relevant items were included in more general scales.

The importance of coping efficacy has nonetheless been stressed by several authors (Lent, Brown, \& Hackett, 2000; Raque-Bogdan, Klingaman, Martin, \& Lucas, 2013). According to Byars-Winston and Fouad (2008, p. 427), "coping efficacy affects emotional reactions as well as behavior, especially related to anxiety and stress reactions to unfamiliar or 


\section{Gender, Barriers, Support, Self-Efficacy and Goals}

potentially aversive situations", and we can certainly regard decision making as a potentially aversive situation. Lent and Brown (2013) also stress the importance of coping skills and processes in career behaviours. Coping efficacy may therefore contribute to the implementation of these skills and processes. Although the specific role of coping efficacy in the career choice model has not been investigated, empirical results indicate significant paths between coping efficacy and other variables of this model. For example, a positive path between social support and coping efficacy has been observed in several studies (Lopez \& Ann-Yi, 2006; Raque-Bogdan et al., 2013). The paths between barriers and coping efficacy have also been investigated. Concerning career barriers, this path was found to be significant and negative in two previous studies (Byars-Winston \& Fouad, 2008; Perrone, Civiletto, Webb, \& Fitch, 2004). These results highlight the relevance of a study that would enable to integrate results observed in diverse studies and so, to show the role of coping efficacy in the career choice model. To our knowledge, the path between coping efficacy and goals has been investigated in one study (Tate et al., 2015). This path was non-significant. According to the authors, their participants took part in a support program and had already chosen an educational goal, so, they would have already identified barriers and decided that they could perceive them. However, we can assume that individuals with high levels of self-efficacy assign themselves high goals because they have no doubts about their ability to overcome any barriers in their way. As coping efficacy was related to contextual variables in previous studies and as coping efficacy is supposed to be related to goals, we can consider coping efficacy as a mediator variable between contextual variables and goals.

The above studies were conducted with science, technology, engineering and mathematics (STEM) students, but the career choice model has also been validated with psychology students. The paths between academic self-efficacy, outcome expectations, interests and goals were investigated by both Ferry, Fouad, and Smith (2000) and Blanco 


\section{Gender, Barriers, Support, Self-Efficacy and Goals}

(2011). Results of these studies corroborated the career choice model. More generally, Fouad, Smith, and Zao (2002) looked at whether the career choice model could be validated in other disciplines (arts, social sciences and English), in a study dealing with paths between academic performances, academic self-efficacy, outcome expectations, interests and goals. Their results indicated that the career choice model does indeed apply to disciplines other than STEM. However, none of the studies performed so far with students in these other disciplines has included social support or perceived barriers.

The career choice model (Lent, 2005) also encompasses person inputs (e.g., gender), which are assumed to be related to contextual influences (social support and perceived barriers). The relationship between gender and barriers was observed in several studies (Cardoso \& Marques, 2008; Lindley, 2005; Lipshits-Braziler \& Tatar, 2012; Luzzo \& McWhirter, 2001; Raque-Bogdan, Klingaman, Martin, \& Lucas, 2013; Watts, Frame, Moffett, Van Hein, \& Hein, 2015). However, in most studies relative to the career choice model, gender is treated as a moderator variable. Moreover, most of the studies that have investigated the moderator effect of gender so far were conducted with students in STEM, where women are underrepresented. The aim of these studies was to devise "theory-based interventions that might promote the greater involvement of women (...) in STEM fields” (Lent et al., 2005, p. 85). Results indicated that the career choice model does not vary across gender (Jiang \& Zhang, 2012; Lent et al., 2005; Lent et al., 2008; Lent et al., 2011). Fouad, Smith and Zao (2002) observed similar results with students from other areas (art, social science and English). This result highlights the relevance to examine whether the results on gender yielded by studies with students in STEM are replicated for disciplines where men are underrepresented.

\section{Purpose of the Current Study}




\section{Gender, Barriers, Support, Self-Efficacy and Goals}

The first objective of this study was to investigate the paths between coping efficacy and other variables in the career choice model. We chose to focus on coping efficacy because the specific role of this particular type of self-efficacy in the career choice model had not previously been investigated, although studies had highlighted significant paths between coping efficacy and contextual variables (Byars-Winston \& Fouad, 2008; Perrone et al., 2004; Raque-Bogdan et al., 2013). In accordance with the career choice model (Lent, 2008) and with previous results, we expected to find significant relationships between barriers, support and coping self-efficacy, as reflected in the following hypotheses:

$\mathrm{H} 1$ : there is a significant negative path between barriers and goals;

$\mathrm{H} 2$ : there is a significant positive path between social support and goals;

H3: there is a significant negative path between barriers and coping efficacy;

H4: there is a significant positive path between social support and coping efficacy;

H5: there is significant positive paths between coping efficacy and goals;

H6: coping efficacy mediates the path between barriers and goals;

H7: coping efficacy mediates the path between social support and goals.

Expected paths are displayed in Figure 1

Insert Figure 1 about here

Our second aim was to investigate the role of gender in these paths. Most previous studies, which were conducted in disciplines where men are more numerous, had reported only minor variations with gender. Our objective was to ascertain whether similar results are found for coping efficacy in disciplines where women are more numerous, such as law, literature and the social sciences (according to a report published in France in 2012, between $64 \%$ and $70 \%$ of students in these disciplines are women; Direction de l'Evaluation, de la Prospective et de la Performance). We hypothesized that gender makes no difference (H8).

\section{Method}




\section{Gender, Barriers, Support, Self-Efficacy and Goals}

\section{Participants and Procedure}

Participants were 215 first-year undergraduates (62 men, 153 women) studying law, art history, literature, the arts or psychology at a university in the South of France. Their ages ranged from 18 to 26 years $(M=20.5, S D=2.5)$. Researchers recruited them before classes. Participants were invited to take part on a voluntary basis in a study concerning vocational activities. They were advised that their responses would be anonymous and would be used for research purposes only. Those who agreed were given questionnaires to complete.

\section{Measures}

We developed French adaptations of four scales described below. These scales were translated by two English-speaking persons, after which translators determined which translation best rendered the meaning of the original item. The translated scales were then administered to some of the participants to make sure that the items were clearly understood.

\section{Perception of barriers.}

We chose the Perception of Barriers Scale (Luzzo \& McWhirter, 2001), in which participants rate items concerning the likelihood of encountering various barriers in their future lives (e.g., lack of support from teachers) on a 5-point Likert scale ranging from strongly disagree to strongly agree. This scale has proven homogeneity and stability (Luzzo \& McWhirter, 2001). The homogeneity of the original scale, as measured with Cronbach's alpha, was .90. Test-retest reliability over a 2-month time period yielded a stability coefficient of .78. The internal consistency of our version of this scale, as measured by Cronbach's alpha, was .82.

\section{Coping with barriers.}

The Coping with Barriers Scale (Luzzo \& McWhirter, 2001) was developed to mirror the Perception of Barriers Scale. It contains two subscales (coping with career-related barriers and coping with educational barriers). Participants have to indicate their degree of confidence 


\section{Gender, Barriers, Support, Self-Efficacy and Goals}

that they can overcome each potential barrier on a 5-point scale ranging from not at all confident to highly confident. It has proven homogeneity and stability (Luzzo \& McWhirter, 2001). Cronbach's alphas were .88 for coping with career barriers and .93 for coping with educational barriers. Test-retest reliability over a 2 -month period was moderately stable $(r=$ .50 for coping with career barriers, $r=.49$ for coping with educational barriers). The internal consistency of our version, as measured by Cronbach's alpha, was .91. A high score corresponded to a high level of coping efficacy.

\section{Educational goals.}

We adapted a questionnaire used by Lent et al. (2003). The original scale contains four items about participants' academic intentions, rated on a 5-point scale ranging from 1 (strongly disagree) to 5 (strongly agree). As it was developed for engineering students, when we translated the items, we reworded them so that they were relevant for students in all disciplines (e.g., "I plan to remain enrolled in the same discipline next year"). The internal consistency of this scale, as measured with Cronbach's alpha, was .92. A high score corresponded to a strong intention to continue in the same discipline.

\section{Social support.}

We developed a French adaptation of the Multidimensional Scale of Perceived Social Support (Zimet et al., 1988). This scale measures social support from different sources, including family members, friends and other persons. The original version contains 12 items (e.g., "I can talk about my problems with my friends"), which respondents rate on a 7-point scale ranging from very strongly disagree to very strongly agree. The psychometric qualities of this scale have been highlighted elsewhere (Zimet, Dahlem, Zimet, \& Farley, 1988). Zimet et al. (1988) found satisfactory internal consistency $(\alpha=.88)$ and high test-retest reliability $(r$ $=.85$ for a $2-3$ month interval). The internal consistency of this scale, as measured with Cronbach's alpha, was .92. A high score meant more social support. 


\section{Gender, Barriers, Support, Self-Efficacy and Goals}

\section{Results}

Descriptive statistics and a correlation matrix are displayed in Table 1. We found significant correlations between goals and perceived barriers, goals and barrier coping efficacy, goals and social support, perceived barriers and coping self-efficacy, barriers and social support, and coping efficacy and social support.

Insert Table 1 about here

We began by conducting mediation analyses, following the guidelines provided by Baron and Kenny (1986). These authors consider that a variable mediates the path between a predictor and a criterion if it meets the following conditions: the predictor (here, barriers or social support) significantly influences the mediator variable (here, coping efficacy); the predictor determines the criterion (here, goals); and the mediator variable significantly influences the criterion. The path between predictor and criterion was significantly reduced when the mediator was introduced in the regression. The Sobel test was used to test the mediation and bootstrapping methods were used to obtain confidence intervals around the indirect effects.

Results of regressions are displayed in Table 2. All these conditions were met for the hypothesis (H6) that coping efficacy mediates the path between barriers and goals. In accordance with $\mathrm{H} 1$ and $\mathrm{H} 3$, barriers were significantly negatively related both to goals and to coping efficacy. Coping efficacy was significantly positively related to goals (H5). When barriers and social support were introduced in the regression, the path between barriers and goals ceased to be significant. Results of the Sobel test confirmed the H6 mediation hypothesis $(z=-2.78, p<.01)$. Results of bootstrapping methods show that the indirect effect is significant $(B=-.19, S E=.08,95 \%$ CI $[-.36,-.04])$. Concerning the hypothesis that coping efficacy mediates the path between social support and goals (H7), results were similar. All paths were significant. In accordance with $\mathrm{H} 2$ and $\mathrm{H} 4$, social support was significantly 


\section{Gender, Barriers, Support, Self-Efficacy and Goals}

positively related to both coping efficacy and goals, while coping efficacy was significantly positively related to goals (H5). When social support and coping efficacy were introduced in the regression, the path between social support and goals became only marginally significant. Results of the Sobel test confirmed the H7 mediation hypothesis $(z=2.57, p<.05)$. Again, results of bootstrapping methods show that the indirect effect is significant $(B=.05, S E=.02$, $95 \%$ CI $[.02, .11])$. Our results indicate that coping self-efficacy fully mediates the path between barriers and goals, and partially mediates the path between social support and goals.

We then tested whether gender moderates these paths, using the Interaction software developed by Soper (2006). Results showed that gender does not moderate the paths between barriers and coping efficacy $(B=.23, t=1.49, p>.05)$, barriers and goals $(B=-.01, t=-.01$, $p>.05)$, or coping efficacy and goals $(B=.41, t=1.70, p>.05)$. Nor does it moderate the paths between social support, coping efficacy and goals (between social support and coping efficacy: $B=.08, t=1.20, p>.05$; between social support and goals: $B=.13, t=1.11, p>$ .05 ; between coping efficacy and goals: $B=.41, t=1.70, p>.05)$. These results corroborate H8.

\section{Discussion}

The aim of this study was to investigate the paths between barriers, social support, barrier coping efficacy and goals, in disciplines where men are underrepresented. A second aim was to investigate whether results vary according to participants' gender. To this end, we administered four scales to a sample of students, and used hierarchical regression and moderation analyses to test our hypotheses.

We assumed that contextual variables (barriers and social support) would be related to goals both directly and indirectly, through coping efficacy. Our results indicated that coping efficacy fully mediates the relationship between barriers and goals, and partially mediates the relationship between social support and goals. Some of the paths we investigated had been 


\section{Gender, Barriers, Support, Self-Efficacy and Goals}

observed in previous studies, such as those between contextual variables and coping efficacy (Byars-Winston \& Fouad, 2008; Lopez \& Ann-Yi, 2006; Perrone et al., 2004; Raque-Bogdan et al., 2013; Thompson, 2013) and between contextual variables and goals (Inda et al., 2013; Lent et al., 2008; Lent et al., 2011). The paths between contextual variables and coping efficacy had been investigated with students from a variety of disciplines, but the ones between contextual variables and goals had mainly been studied with students in STEM. The fact that we found these paths to be significant indicates that the results obtained with students in STEM are similar to those obtained with students in other disciplines. Our results not only highlighted a significant path between coping efficacy and goals, but also confirmed that coping efficacy mediates the paths between contextual variables and goals. To our knowledge, no previous study had suggested that it might play this role. Our results underscore the relevance of investigating the paths between coping efficacy and contextual variables for disciplines where men are underrepresented.

We also looked at whether our results varied according to participants' gender. In line with expectations and with results reported in previous studies featuring a general scale (selfefficacy and coping efficacy items), we failed to observe any gender differences in the paths we found (Lent et al., 2005; Lent et al., 2008; Lent et al., 2011). This suggests that results concerning gender differences are similar regardless of discipline and type of self-efficacy.

\section{Limitations and Suggestions for Future Research}

The present study had several limitations. First, we used self-report data. This method may artefactually increase correlations between variables, particularly when the data are cross-sectional, as they were in our study, and prevented us from interpreting the paths we observed as causal relations. A longitudinal design would allow us to overcome this limitation. Second, our model did not include outcome expectations, academic self-efficacy, or interests. Including these variables would have allowed us not only to compare our results 


\section{Gender, Barriers, Support, Self-Efficacy and Goals}

with those of previous studies more easily, but also to examine the relative roles of academic versus coping efficacy. Byars-Winston and Fouad (2008) observed not only that these types of self-efficacy are related, but also that they are differentially related to contextual variables. These authors found that coping efficacy is related to perceived career barriers, and academic self-efficacy to parental involvement. Their study therefore seems to highlight the relevance of differentiating between types of self-efficacy to investigate the paths between each type and other variables of the model. Third, this research needs to be replicated in other disciplines, to make sure that the career choice model can be applied whatever the discipline. It also needs to be replicated with students in STEM, to check that including coping efficacy in the career choice model is relevant with such samples. Fourth, because our sample of men was small, we could not use structural equation modelling to test our hypotheses, as previous studies have done.

\section{Implications for Counselling}

These results highlight the need to develop interventions based on perceived barriers, social support and coping efficacy. Lent (2005) identified several activities that could help people cope with barriers and build support (e.g., identifying and anticipating possible barriers to choice implementation, analysing the likelihood of encountering these barriers, preparing barrier-coping strategies, and cultivating support for goals). Nota et al. (2014, p. 255) also suggested ways of improving support (e.g., "identification of persons, that could help clients to implement their career goals and to prevent possible future barriers"). The effect of an intervention based on this type of activity was investigated (Turner \& Conkel, 2010). This intervention had a positive effect on social support, but its effect on goal setting was not significant. Barrier anticipation is included in the JOBS program (Price \& Vinokur, 1995; Vinokur \& Schul, 1997). One aim of this program is to inoculate against setbacks through the identification of possible barriers, the generation of solutions and training to overcome these 


\section{Gender, Barriers, Support, Self-Efficacy and Goals}

barriers. Another aim is to identify work-life goals. This program was adapted to favour students' school-to-work transition (Koivisto, Vuori, \& Vinokur, 2010), but to our knowledge, the effect of this program on perceived barriers and coping efficacy was not investigated. Additional studies are therefore needed to explore interventions based on social support, barrier and coping efficacy, and examine whether these interventions have significant effects on these variables and on goals.

\section{References}

Baron, R. M., \& Kenny, D. A. (1986). The moderator-mediator variable distinction in social psychological research: Conceptual, strategic, and statistical considerations. Journal of Personality and Social Psychology, 51(6), 1173-1182. doi: 10.1037/00223514.51.6.1173

Blanco, Á. (2011). Applying social cognitive career theory to predict interests and choice goals in statistics among spanish psychology students. Journal of Vocational Behavior, 78(1), 49-58. doi: 10.1016/j.jvb.2010.07.003

Byars-Winston, A. M., \& Fouad, N. A. (2008). Math and science social cognitive variables in college students: Contributions of contextual factors in predicting goals. Journal of Career Assessment, 16(4), 425-440. doi: 10.1177/1069072708318901

Cardoso, P., \& Marques, J. F. (2008). Perception of career barriers: The importance of gender and ethnic variables. International Journal for Educational and Vocational Guidance, 8(1), 49-61.

Direction de l'évaluation, de la prospective et de la performance. (2012). Filles et garçons sur le chemin de l'égalité de l'école à l'enseignement supérieur. Retrieved from http://www.education.gouv.fr 


\section{Gender, Barriers, Support, Self-Efficacy and Goals}

Ferry, T. R., Fouad, N. A., \& Smith, P. L. (2000). The role of family context in a social cognitive model for career-related choice behavior: A math and science perspective. Journal of Vocational Behavior, 57(3), 348-364. doi: 10.1006/jvbe.1999.1743

Fouad, N. A., Smith, P. L., \& Zao, K. E. (2002). Across academic domains: Extensions of the social-cognitive career model. Journal of Counseling Psychology, 49(2), 164-171. doi: 10.1037/0022-0167.49.2.164

Garriott, P. O., Flores, L. Y., \& Martens, M. P. (2013). Predicting the math/science career goals of low-income prospective first-generation college students. Journal of Counseling Psychology, 60(2), 200-209. doi: 10.1037/a0032074

Inda, M., Rodríguez, C., \& Peña, J. V. (2013). Gender differences in applying social cognitive career theory in engineering students. Journal of Vocational Behavior, 83(3), 346-355. doi: 10.1016/j.jvb.2013.06.010

Jiang, Z.-P., \& Zhang, Z.-R. (2012). Using social cognitive career theory to predict the academic interests and goals of Chinese middle vocational-technical school students. Public Personnel Management, 41(5, Spec Iss), 59-68. doi: $10.1177 / 009102601204100506$

Koivisto, P., Vuori, J., \& Vinokur, A. D. (2010). Transition to work: Effects of preparedness and goal construction on employment and depressive symptoms. Journal of Research on Adolescence, 20(4), 869-892. doi: 10.1111/j.1532-7795.2010.00667.x

Lent, R. W. (2005). A social cognitive view of career development and counseling. In S. D. Brown \& R. W. Lent (Eds.), Career development and counseling: Putting theory and research to work. (pp. 101-127). Hoboken, NJ US: John Wiley \& Sons Inc.

Lent, R. W. (2008). Une conception sociale cognitive de l'orientation scolaire et professionnelle: Considérations théoriques et pratiques. Orientation Scolaire et Professionnelle, 37(1), 57-90. 


\section{Gender, Barriers, Support, Self-Efficacy and Goals}

Lent, R. W., \& Brown, S. D. (2013). Social cognitive model of career self-management: Toward a unifying view of adaptive career behavior across the life span. Journal of Counseling Psychology, 60(4), 557-568. doi: 10.1037/a0033446

Lent, R. W., Brown, S. D., \& Hackett, G. (2000). Contextual supports and barriers to career choice: A social cognitive analysis. Journal of Counseling Psychology, 47(1), 36-49. doi: $10.1037 / 0022-0167.47 .1 .36$

Lent, R. W., Brown, S. D., Schmidt, J., Brenner, B., Lyons, H., \& Treistman, D. (2003). Relation of contextual supports and barriers to choice behavior in engineering majors: Test of alternative social cognitive models. Journal of Counseling Psychology, 50(4), 458-465. doi: 10.1037/0022-0167.50.4.458

Lent, R. W., Brown, S. D., Sheu, H.-B., Schmidt, J., Brenner, B. R., Gloster, C. S., . . Treistman, D. (2005). Social Cognitive Predictors of Academic Interests and Goals in Engineering: Utility for Women and Students at Historically Black Universities. Journal of Counseling Psychology, 52(1), 84-92. doi: 10.1037/0022-0167.52.1.84

Lent, R. W., Lopez, A. M., Jr., Lopez, F. G., \& Sheu, H.-B. (2008). Social cognitive career theory and the prediction of interests and choice goals in the computing disciplines. Journal of Vocational Behavior, 73(1), 52-62. doi: 10.1016/j.jvb.2008.01.002

Lent, R. W., Lopez, F. G., Sheu, H.-B., \& Lopez, A. M., Jr. (2011). Social cognitive predictors of the interests and choices of computing majors: Applicability to underrepresented students. Journal of Vocational Behavior, 78(2), 184-192. doi: 10.1016/j.jvb.2010.10.006

Lindley, L. D. (2005). Perceived barriers to career development in the context of social cognitive career theory. Journal of Career Assessment, 13(3), 271-287. 


\section{Gender, Barriers, Support, Self-Efficacy and Goals}

Lipshits-Braziler, Y., \& Tatar, M. (2012). Perceived career barriers and coping among youth in Israel: Ethnic and gender differences. Journal of Vocational Behavior, 80(2), 545554.

Lopez, F. G., \& Ann-Yi, S. (2006). Predictors of career indecision in three racial/ethnic groups of college women. Journal of Career Development, 33(1), 29-46. doi: $10.1177 / 0894845306287341$

Luzzo, D. A., \& McWhirter, E. H. (2001). Sex and ethnic differences in the perception of educational and career-related barriers and levels of coping efficacy. Journal of Counseling \& Development, 79(1), 61-67. doi: 10.1002/j.1556-6676.2001.tb01944.x

Navarro, R. L., Flores, L. Y., \& Worthington, R. L. (2007). Mexican American middle school students' goal intentions in mathematics and science: A test of social cognitive career theory. Journal of Counseling Psychology, 54(3), 320-335. doi: 10.1037/00220167.54.3.320

Nota, L., Soresi, S., Ferrari, L., \& Ginevra, M. C. (2014). Vocational designing and career counseling in Europe: Challenges and new horizons. European Psychologist, 19(4), 248-259. doi: 10.1027/1016-9040/a000189

Perrone, K. M., Civiletto, C. L., Webb, L. K., \& Fitch, J. C. (2004). Perceived barriers to and supports of the attainment of career and family goals among academically talented individuals. International Journal of Stress Management, 11(2), 114-131. doi: $10.1037 / 1072-5245.11 .2 .114$

Price, R. H., \& Vinokur, A. D. (1995). Supporting career transitions in a time of organizational downsizing: The Michigan JOBS Program. In M. London (Ed.), Employees, careers and job creation: Developing growth-oriented human resource strategies and programs (pp. 191-209). San Francisco: Jossey-Bass Publishers. 


\section{Gender, Barriers, Support, Self-Efficacy and Goals}

Raque-Bogdan, T. L., Klingaman, E. A., Martin, H. M., \& Lucas, M. S. (2013). Career-related parent support and career barriers: An investigation of contextual variables. The Career Development Quarterly, 61(4), 339-353. doi: 10.1002/j.21610045.2013.00060.x

Soper, D. S. (2006). Interaction [Computer software]. Retrieved from http://www.danielsoper.com/Interaction.

Tate, K. A., Fouad, N. A., Marks, L. R., Young, G., Guzman, E., \& Williams, E. G. (2015). Underrepresented first-generation, low-income college students' pursuit of a graduate education: Investigating the influence of self-efficacy, coping efficacy, and family influence. Journal of Career Assessment, 23(3), 427-441. doi: $10.1177 / 1069072714547498$

Thompson, M. N. (2013). Career barriers and coping efficacy among Native American students. Journal of Career Assessment, 21(2), 311-325. doi: $10.1177 / 1069072712471501$

Turner, S. L., \& Conkel, J. L. (2010). Evaluation of a career development skills intervention with adolescents living in an inner city. Journal of Counseling \& Development, 88(4), 457-465. doi: 10.1002/j.1556-6678.2010.tb00046.x

Vinokur, A. D., \& Schul, Y. (1997). Mastery and inoculation against setbacks as active ingredients in the JOBS intervention for the unemployed. Journal of Consulting and Clinical Psychology, 65(5), 867-877. doi: 10.1037/0022-006X.65.5.867

Watts, L. L., Frame, M. C., Moffett, R. G., Van Hein, J. L., \& Hein, M. (2015). The relationship between gender, perceived career barriers, and occupational aspirations. Journal of Applied Social Psychology, 45(1), 10-22. doi: 10.1111/jasp.12271 


\section{Gender, Barriers, Support, Self-Efficacy and Goals}

Zimet, G. D., Dahlem, N. W., Zimet, S. G., \& Farley, G. K. (1988). The Multidimensional Scale of Perceived Social Support. Journal of Personality Assessment, 52(1), 30-41. doi: 10.1207/s15327752jpa5201_2 


\section{Gender, Barriers, Support, Self-Efficacy and Goals}

Figure 1

Model depicting expected paths between social support, barriers, coping efficacy and goals.

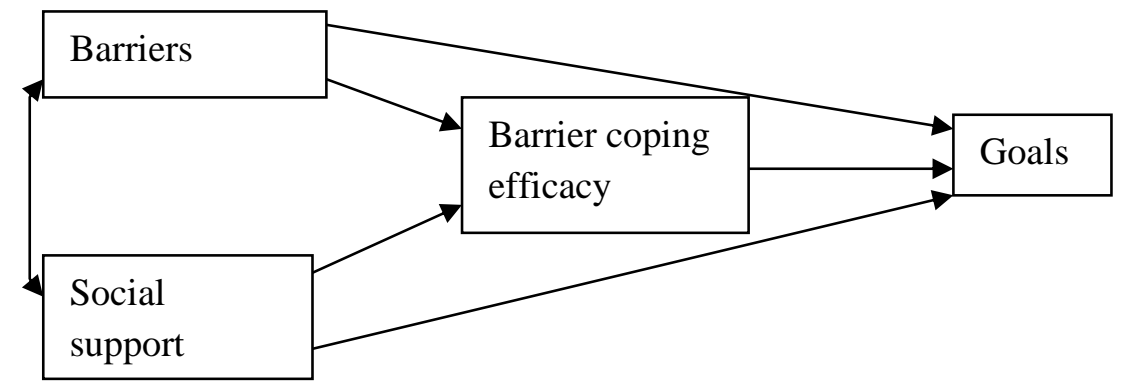




\section{Gender, Barriers, Support, Self-Efficacy and Goals}

Table 1

Descriptive Statistics and Correlation Matrix

\begin{tabular}{|c|c|c|c|c|c|c|}
\hline & $M$ & $S D$ & 1 & 2 & 3 & 4 \\
\hline 1. Gender $^{\mathrm{a}}$ & 1.71 & .45 & & & & \\
\hline 2. Social support & 5.42 & 1.20 & $.31 * *$ & & & \\
\hline 3. Barriers & 2.86 & .48 & .08 & $-.32 * *$ & & \\
\hline 4. Barrier coping efficacy & 3.58 & .57 & $-.19 * *$ & $.27 * *$ & $-.41 * *$ & \\
\hline 5. Goals & 4.17 & .99 & .05 & $.18^{* *}$ & $-.19 * *$ & $.26^{* *}$ \\
\hline
\end{tabular}




\section{Gender, Barriers, Support, Self-Efficacy and Goals}

Table 2

Results of the Regressions on Goals

\begin{tabular}{lllll}
\hline Predictors & Barriers & \multicolumn{2}{c}{ Social support } \\
\hline & $R^{2}$ & Beta & $R^{2}$ & Beta \\
& & & & \\
\hline Step 1 (predictor $\rightarrow$ mediator variable) & $.17^{* * *}$ & & $.07^{* * *}$ & \\
Barriers & & & & \\
& & $-.41^{* * * *}$ &
\end{tabular}

Social support

Step 2 (predictor $\rightarrow$ criterion)

$.03^{* *}$ $.03^{* *}$

Barriers

$-.18 * *$

Social support

Step 3 (mediator variable $\rightarrow$ criterion)

$.06^{* * *} \quad .06^{* * *}$

Coping efficacy

Step 4 (predictor and mediator variable $\rightarrow$ criterion) $.07 * * *$

$.07 * * *$

Barriers

Social support

Coping efficacy

$* p<.05 . * * p<.01 . * * * p<.001$. 